\title{
A geophone-based and low-cost data acquisition and analysis system designed for microtremor measurements
}

\author{
Ozkan Kafadar \\ Department of Computer Programming, Kocaeli University, 41140 Kocaeli, Turkey \\ Correspondence: Ozkan Kafadar (okafadar@kocaeli.edu.tr)
}

Received: 27 April 2020 - Discussion started: 26 May 2020

Revised: 22 July 2020 - Accepted: 29 July 2020 - Published: 4 September 2020

\begin{abstract}
The commercial data acquisition instruments designed for three-component microtremor measurements are usually very expensive devices. In this paper, a low-cost, computer-aided, and geophone-based system designed to record, monitor, and analyze three-component microtremor data is presented. This proposed system is not a simple data acquisition system. It is also an integrated system developed to interpret the microtremor data using the horizontalto-vertical spectral ratio $(\mathrm{H} / \mathrm{V})$ method without any external software. Therefore, the H / V peak frequency and amplitude can be easily estimated using this system. The proposed system has several features such as a $200 \mathrm{~Hz}$ sampling frequency, approximately $72 \mathrm{~dB}$ dynamic range, text data format, and data analysis tools. This system consists of a graphical user interface developed by using the .NET Framework 4.5.2 and external hardware that includes signal conditioning circuits, voltage converter circuit, external analogto-digital converter, and Arduino Uno board. The proposed system uses low-cost vertical and horizontal geophones with a $4.5 \mathrm{~Hz}$ natural frequency to measure three-component microtremor data. The developed software undertakes many tasks such as communication between the external hardware and computer, transferring, monitoring, and recording the seismic data to the computer, and interpretation of the recorded data using the Nakamura method. Channel consistency and internal noise measurement tests were performed to demonstrate the accuracy and precision of the proposed system. The proposed system was compared to a commercial triaxial digital seismograph, and satisfactory results were obtained. The developed system is a completely open-source and open-hardware system and can be easily used in academic studies conducted by researchers and university students who are interested in seismic ambient noise analysis.
\end{abstract}

\section{Introduction}

The fundamental principle of seismic methods is based on the recording of seismic waves generated by natural or synthetic sources. There are two types sensors, called velocimeters and accelerometers, with different bandwidths and sensing mechanisms to measure these seismic oscillations. These sensors measure the ground motion as velocity and acceleration and convert the ground motion into a measurable electrical signal. Accelerometers are electromechanical devices, which measure acceleration, and are generally used for specific purposes such as vibration and inclination measurements. On the other hand, geophones are velocimeters, which are often preferred in local seismic applications because of their excellent reliabilities and high sensitivities. Accelerometers are generally less sensitive than velocimeters and are also used in strong ground motion measurements. Broadband velocimeters have a larger passband than geophones and can measure ground motions with frequencies ranging from 0.001 to $500 \mathrm{~Hz}$. Classical short-period velocimeters are constituted by three orthogonally mounted geophones that have natural frequencies of a few hertz. Data acquisition systems are needed to digitize the analog signals detected by these sensors and to store them in a data storage device. Recently, many studies have been performed to design seismic data acquisition systems. In a study by Khan et al. (2012), a software component was developed to digitize analog seismic signals using the computer sound card. Llorens et al. (2016) designed a simple data acquisition system for recording seismic data detected by the vertical geophone to an external SD card. In a previous study, we developed hardware and software for the seismic refraction method (Kafadar and Sertcelik, 2016). In another study, hardware was designed for recording seismic noise (Llorens et al., 2018). 
In this paper, a low-cost, computer-aided, and Arduinobased three-component microtremor measurement and analysis system (MicDAC) is presented. In the literature, there are many data acquisition and analysis systems developed using Arduino boards for scientific purposes (Llorens et al., 2016; Fisher and Gould, 2012; Huang et al., 2018; Puente et al., 2017). MicDAC is controlled through a user-friendly graphical interface (MicDAC-GUI) developed by using the Microsoft .NET Framework 4.5.2 platform and C\# language. MicDAC is not a simple digitizer. It is an analysis tool that can interpret recorded ambient noise using the Nakamura method (Nakamura, 1989), and it can calculate the two parameters $(\mathrm{H} / \mathrm{V}$ peak frequency and amplitude) most important in designing earthquake-resistant structures. This study is completely different from the literature since the proposed system does not require any external software. It can display the calculated Fourier spectra for three-component ambient noise in real time. This feature provides pre-information about the frequencies of ambient noise in the survey area before starting measurements.

\section{Horizontal-to-vertical spectral ratio $(\mathrm{H} / \mathrm{V})$ method}

Except for earthquakes and seismic explosions, the vibrational movements of the Earth that occur naturally (winds, oceanic waves, and geothermal reactions) or artificially (traffic and industrial machines) with periods that do not exceed a few minutes are called microseisms (Katz, 1976). The term microtremor is used for periods ranging between 0.05 and $2 \mathrm{~s}$. In other words, microtremors are low-amplitude (1$10 \mu \mathrm{m})$ and low-frequency $(0.5-20 \mathrm{~Hz})$ oscillations. Therefore, broadband seismometers are used to measure these seismic waves.

Microtremors have been classified by some researchers. According to Aki (1957) and Frantti (1963), microtremors are surface waves. Other researchers claim that microtremors are body waves (Kanai, 1962; Douze, 1964). In general, surface sources such as wind, ocean waves, and cultural noise generate surface waves, whereas naturally occurring Earth tremors with an extremely small amplitude generate body waves (Weller, 1974).

The horizontal-to-vertical spectral ratio $(\mathrm{H} / \mathrm{V})$ technique proposed by Nakamura (1989) is one of the most popular methods developed for the analysis of microtremor data. This method, based on single-station microtremor data analysis, can easily minimize the source effect by normalizing the horizontal spectral amplitude with the vertical spectral amplitude. The first step to evaluate microtremor data using the $\mathrm{H} / \mathrm{V}$ technique is to remove the offsets for each seismic component. This process is performed by subtracting the mean value of signals from each time-domain signal in seismic data. Optionally, a low-pass filter can be applied to the recorded signal to remove the high-frequency components. Then, tapering and fast Fourier transform operations are applied to each selected time window. The recorded microtremor data are generally split into shorter time windows before starting the analysis process. It is a standard practice to multiply these windows by a taper before performing a Fourier spectrum. The cosine tapers are usually preferred in seismic data analysis. They minimize the discontinuity effect between the ends of the time series (Percival and Walden, 1993).

Raw spectra contain many frequency samples. KonnoOhmachi smoothing is widely used to smooth the Fourier spectrum (Konno and Ohmachi, 1998). This process is not mandatory but is strongly recommended. In this study, the quadratic mean is used to calculate the average of two horizontal components. The SESAME (Site Effects Assessment using Ambient Excitations) project is the most comprehensive study performed to interpret $\mathrm{H} / \mathrm{V}$ curves (SESAME, 2004). In the SESAME report, the required conditions to interpret the $\mathrm{H} / \mathrm{V}$ curves correctly are described in detail.

\section{System architecture and design}

MicDAC consists of a developed graphical user interface and external hardware that includes amplifiers, low-pass and notch filter circuits, clipper circuits, voltage converter circuit, external analog-to-digital converter, and Arduino Uno board. The graphical abstract of MicDAC is shown in Fig. 1. The designed external hardware is connected to the computer via a USB. It utilizes the USB port as a power supply. Thus, no external battery is required.

\subsection{Hardware implementation}

The vertical and horizontal geophones manufactured by the EGL Company were used to measure three-component microtremor data. They have some characteristic features such as a natural frequency of $4.5 \pm 10 \% \mathrm{~Hz}$, typical spurious frequency greater than $150 \mathrm{~Hz}$, damping of $0.6 \pm 5 \%$, and open circuit sensitivity of $28.8 \pm 5 \% \mathrm{~V} \mathrm{~m}^{-1} \mathrm{~s}^{-1}$. The external view, amplitude response, and phase response of these geophones are shown in Fig. 2. There are also geophones with lower frequency on the market, but the price of these instruments increases exponentially with decreasing frequencies. Moreover, the cost of high-quality broadband seismometers can reach a mid-level car price. For this reason, in this paper a low-cost hardware-software device is presented to both measure and interpret three-component microtremor data. The estimated costs of the electronic components of the designed external hardware in this study are presented in Table 1 . The total cost of the hardware, including the sensors, is approximately EUR 255.

The output of a geophone consists of two poles, and its output voltage is too weak to be recorded without amplification. The voltage difference between these poles can be measured by using various operational amplifiers. The first stage 


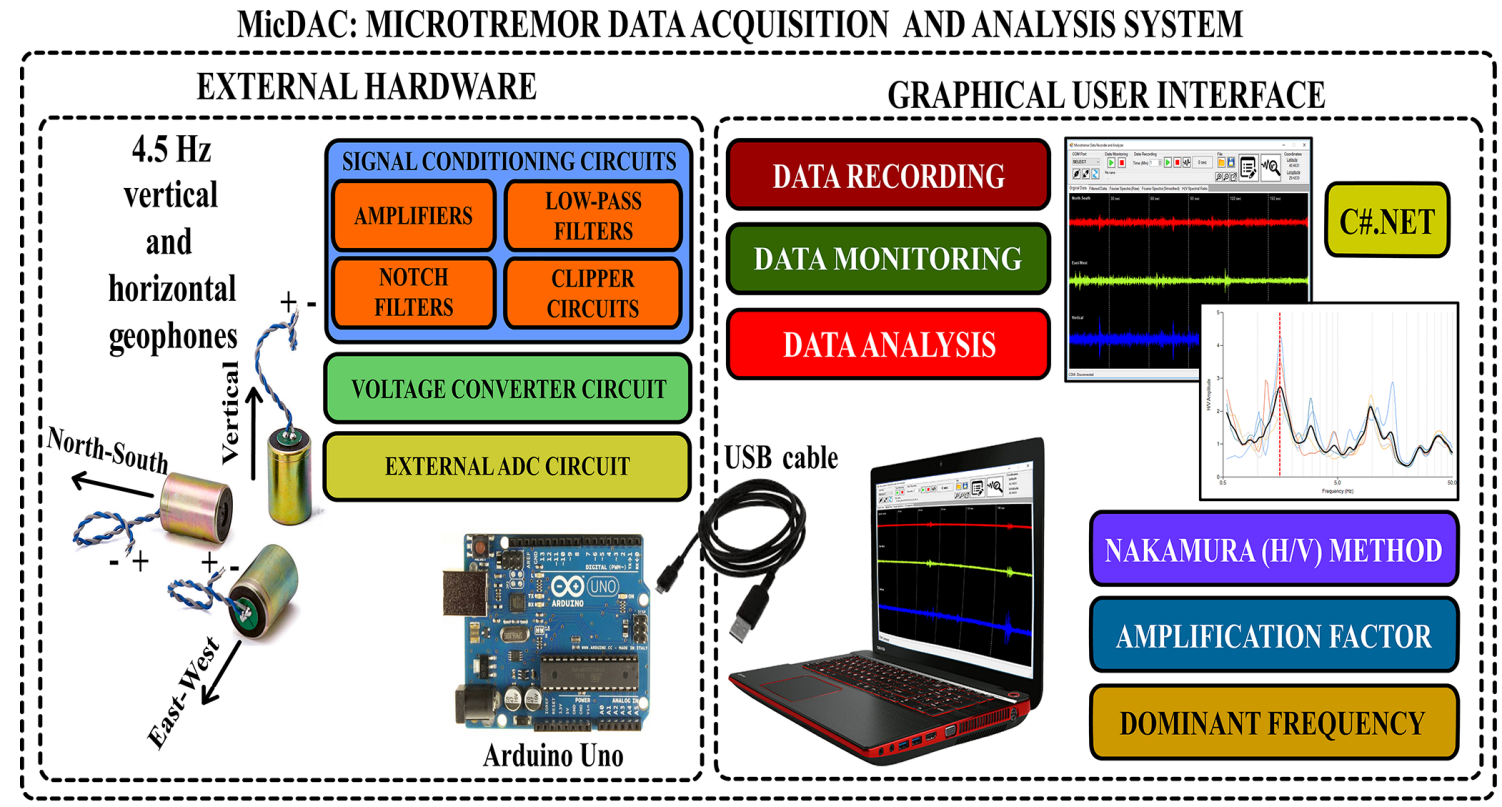

Figure 1. Graphical abstract of the proposed system for measurement and analysis of three-component microtremor data.

Table 1. List of the electronic components.

\begin{tabular}{lllr}
\hline Components & Source & Total & Cost (EUR) \\
\hline 4.5 Hz vertical geophone & Sentez System & $\times 1$ & 65.0 \\
4.5 Hz horizontal geophone & Sentez System & $\times 2$ & 70.0 \\
Arduino UNO + USB cable & Int-El Electronic & $\times 1$ & 21.0 \\
ICL7660 DC-DC converter & Int-El Electronic & $\times 1$ & 1.0 \\
INA122 instrumentation amplifier & Int-El Electronic & $\times 3$ & 5.5 \\
OP07CP operational amplifier & Int-El Electronic & $\times 3$ & 0.3 \\
MCP3208 12 bit ADC & Int-El Electronic & $\times 1$ & 3.0 \\
Resistor, capacitor, diode, potentiometer, DIP switch, & Int-El Electronic & & 4.0 \\
connector, jumper cable, crocodile cable & & & \\
Breadboard & Int-El Electronic & $\times 3$ & 1.1 \\
\hline
\end{tabular}

of this signal conditioning circuit consists of differentialinput and single-output INA122 amplifiers from Texas Instruments (1997). These amplifiers are instrumentation amplifiers with very important properties such as low-noise $(60 \mathrm{nV} / \sqrt{\mathrm{Hz}})$, high-quality, and rail-to-rail output, wide power supply range (single supply: 2.2 to $36 \mathrm{~V}$, dual supply: $-0.9 /+1.3$ to $-18 /+18 \mathrm{~V})$, low offset voltage $(250 \mu \mathrm{A}$ $\max )$, and low quiescent current $(60 \mu \mathrm{A})$.

In this study, symmetrical power supplies $( \pm 5 \mathrm{~V})$ were used to supply these amplifiers. The Arduino Uno board can only provide 3.3 and $5 \mathrm{~V}$ positive outputs. For this reason, the ICL7660 integrated circuit was used to obtain the negative power supply $(-5 \mathrm{~V})$ from the positive power supply $(+5 \mathrm{~V})$. The pin connections of the ICL7660 voltage converter and INA122 amplifier are shown in Fig. 3. It can be set to four different gain levels $(46,56,60$, and $66 \mathrm{~dB})$ for each channel thanks to the DIP switch and resistors connected to pins 1 and 8 of the INA122 amplifiers.

The next step in the external hardware is a passive RC (resistor-capacitor) low-pass circuit, which is used to attenuate the high-frequency components in the amplified signal and to avoid the aliasing phenomenon. The cutoff frequency of the low-pass filter was set at approximately $22 \mathrm{~Hz}$ because the corresponding frequency range in microtremor studies is 0-20 Hz. In the last stage of the signal conditioning circuits, the Twin-T notch filters and clipper circuits were used to remove the $50 \mathrm{~Hz}$ interferences and to clip the negative voltage in the output signal, respectively (Fig. 3). Instead of the internal 10 bit analog-to-digital converter on the Arduino board, the MCP3208 12 bit external analog-to-digital converter was preferred to ensure higher-resolution signals. 
(a)

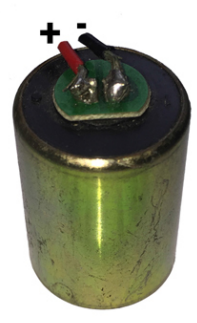

(b)

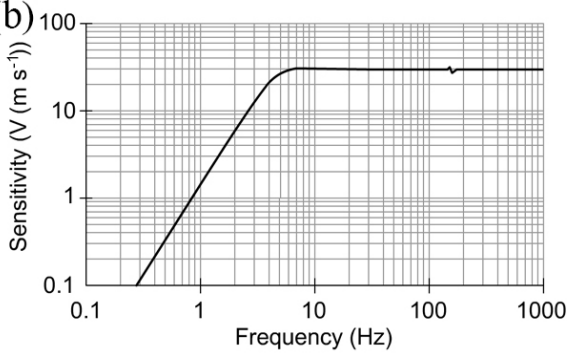

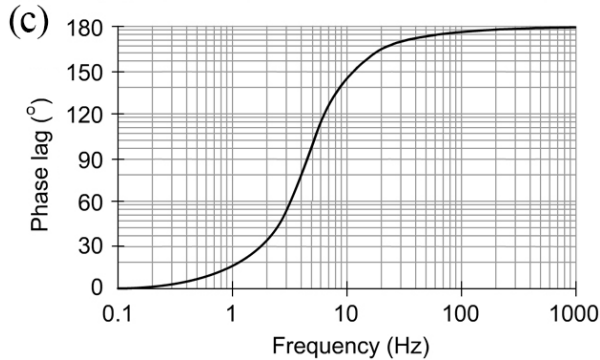

Figure 2. For the geophones with a $4.5 \mathrm{~Hz}$ natural frequency, (a) external view, (b) amplitude response, and (c) phase response.

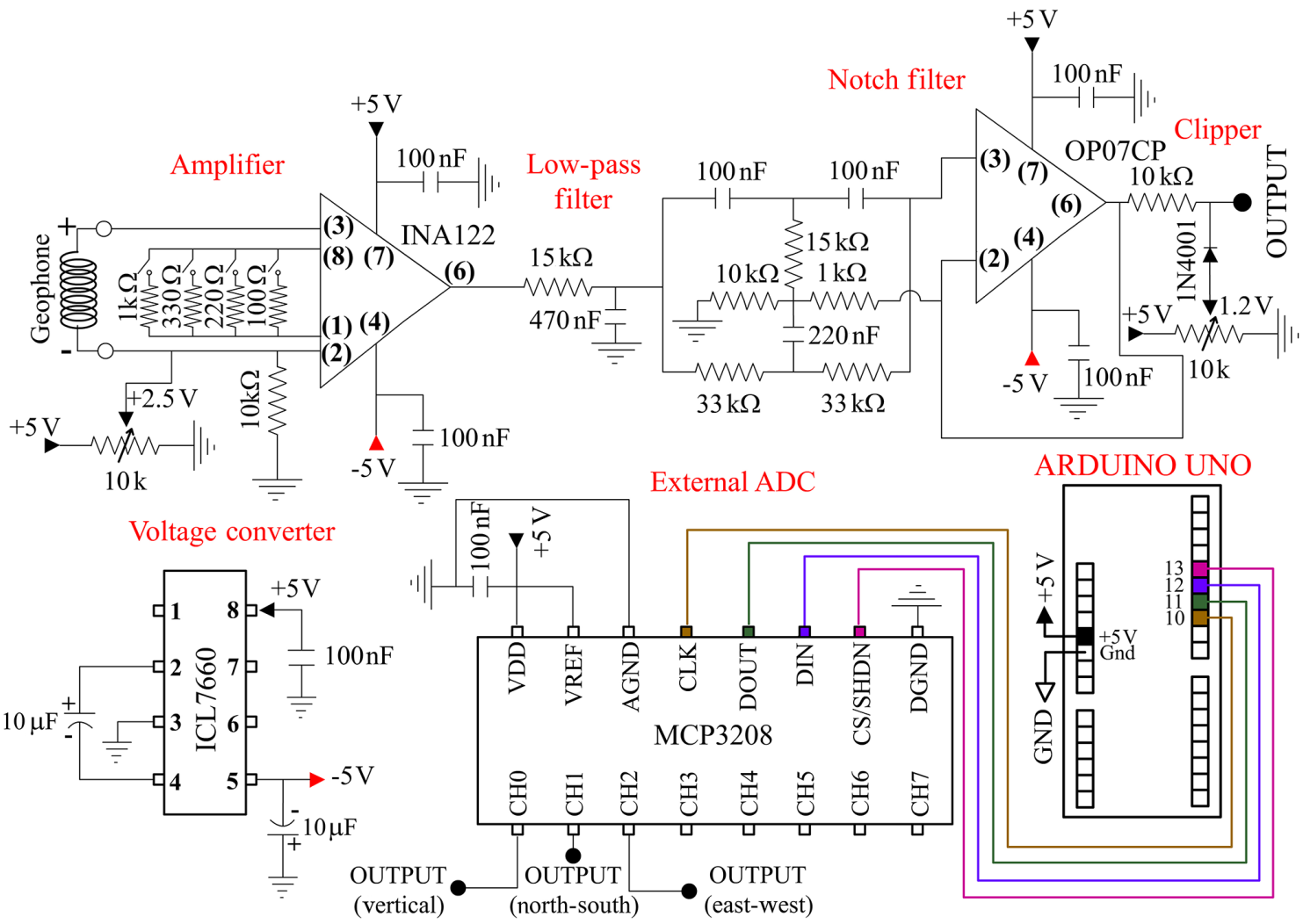

Figure 3. Schematics of external hardware and pin connections.

\subsection{Software implementation}

The MicDAC sketch (Arduino uses the term sketch for a program) was compiled with Arduino version 1.8.8 and stored as a file called MicDAC.ino. This sketch digitizes seismic data with a $200 \mathrm{~Hz}$ sampling frequency and transfers the digitized data to the computer via USB. The second program (MicDAC-GUI), developed by using .NET Framework 4.5.2 in $\mathrm{C \#}$ language, is a user-friendly and Windows operatingsystem-based software. The MicDAC-GUI consists of data monitoring mode, data recording mode, and analysis tools. It detects the available COM ports automatically. The data monitoring mode is used to display three-component microtremor data in real time and to test the geophones before starting the recording operation. In addition, this mode is also used to adjust the offset needed to see signals symmetrically through the $10 \mathrm{~K}$ potentiometer, a component of the external hardware (Fig. 3). The data recording mode is used to record three-component microtremor data during the desired time.

The MicDAC-GUI allows for performing records with a maximum of $180 \mathrm{~min}$. When the recording operation ends, the user is alerted with an alarm and the temporary data are saved into a file called "datam.txt". The microtremor data are stored in a text file. This data file consists of three columns: V (vertical), NS (north-south), and EW (east-west) components. The recorded signal values vary in the range between 0 and 4095 because the analog-to-digital converter is 12 bit. 

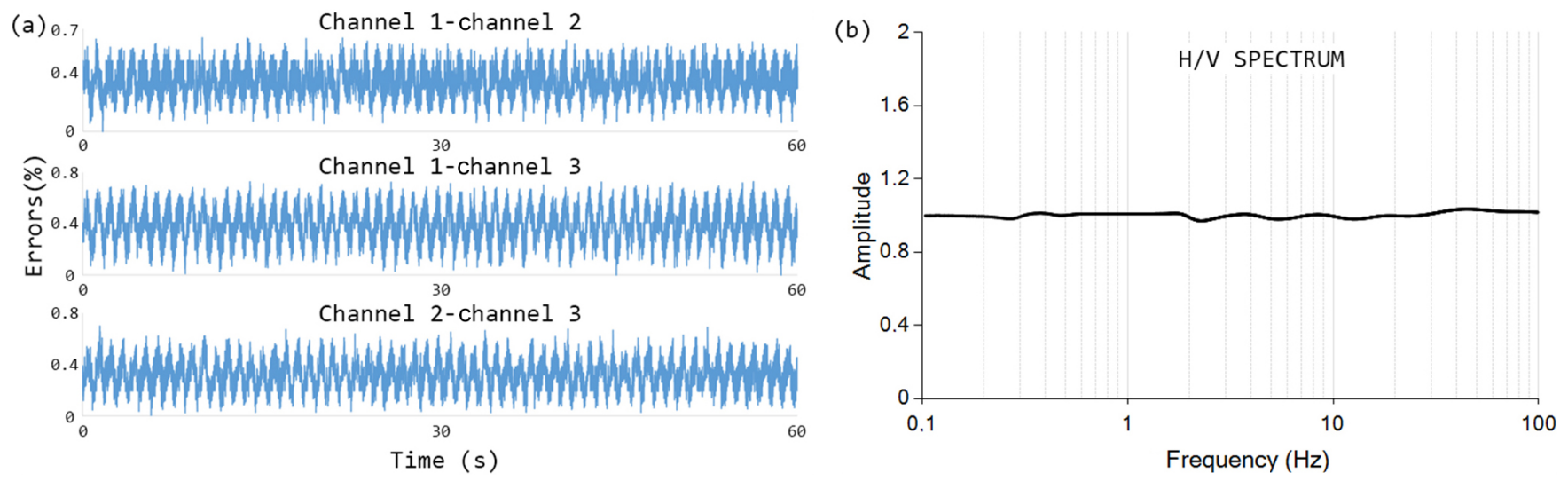

Figure 4. (a) Error percentage of difference signal estimated during the first channel consistency test; (b) H / V spectral ratio.

The coordinates of the survey area and descriptions are stored in a file with info extension.

The MicDAC-GUI allows many operations such as lowpass filtering, tapering, windowing, and smoothing on the recorded data. The desired signals can be selected thanks to the windowing feature of the MicDAC-GUI. The window length $(10.24,20.48,40.96,81.92$, and $163.83 \mathrm{~s})$ is a user-defined parameter. The time duration of the analysis process increases or decreases depending on the number of enabled time windows and data length. The frequency distribution of each window is displayed separately. This feature gives an idea about the windows that will be used in the analysis. Finally, the horizontal-to-vertical spectral ratios for each selected time window are calculated. The calculated $\mathrm{H} / \mathrm{V}$ spectral ratios are also numerically displayed using a grid component. After the analysis process ends, the parameters (cutoff frequency of low-pass filter, taper ratio, length of time window, bandwidth of Konno-Ohmachi smoothing function), raw data, low-pass-filtered data, Fourier amplitude spectra data, smoothed Fourier amplitude spectra data, and $\mathrm{H} / \mathrm{V}$ spectra data are saved into a text file with the "soln" extension.

\subsection{The reliability and accuracy tests of MicDAC}

Three tests were performed in order to demonstrate the accuracy and precision of MicDAC: (1) channel consistency tests using synthetic and real data; (2) internal noise measurement test; and (3) comparison of the characteristics and frequency contents of recorded signals using the proposed system and a commercial microtremor measurement device.

The channel consistency test was performed to evaluate the time-amplitude differences for each channel. Firstly, a $1 \mathrm{~Hz}$ sinusoidal signal of $15 \mathrm{mV}$ amplitude generated by the model FG-8002 function generator manufactured by EZ Digital was connected to each input channel, and these signals were recorded over a period of $60 \mathrm{~s}$ with a $46 \mathrm{~dB}$ gain. After that, the differences of the recorded signals for each channel
Table 2. $\mathrm{H}$ / V peak frequencies and amplitudes calculated from the data recorded simultaneously by GeoBox and MicDAC.

\begin{tabular}{lrr}
\hline & GeoBox & MicDAC \\
\hline H / V peak frequency $(\mathrm{Hz})$ & 3.5034 & 3.4919 \\
H / V peak amplitude & 8.8663 & 8.9264 \\
\hline
\end{tabular}

were calculated. As shown in Fig. 4a, the error percentages of the difference signals (channel 1-channel 2, channel 1channel 3, and channel 2-channel 3) are lower than 1\%. The $\mathrm{H} / \mathrm{V}$ ratios were calculated using the same sinusoidal signals recorded by three channels and presented in Fig. 4b. The $\mathrm{H} / \mathrm{V}$ ratio will be equal to 1 because the same sinusoidal signals were applied to each channel input.

Secondly, a channel consistency test was conducted with real sensors. For this purpose, the same vertical geophone, placed on a table, was connected to the inputs of each channel and the ambient noise was recorded over a period of $180 \mathrm{~s}$ (Fig. 5). In this test, the calculated Fourier spectra were utilized to demonstrate the frequency contents of three channels. The calculated Fourier spectra and H / V ratio are shown in Fig. 6a and b, respectively.

In the next test, the internal noise of MicDAC was recorded during a time period of $60 \mathrm{~s}$ with a $200 \mathrm{~Hz}$ sampling frequency (Fig. 7). The noise levels of three channels were observed as approximately \pm 3 counts $(7.3242 \mathrm{mV}$, $9.39 \times 10^{-5} \mathrm{~m} \mathrm{~s}^{-1}$ ).

Finally, MicDAC was compared with a triaxial digital seismograph called GeoBox manufactured by SARA Electronic Instruments. GeoBox is an instrument designed especially for recording ambient seismic noise, and its different versions with sensors of 2 and $4.5 \mathrm{~Hz}$ are available on the market. In this study, the SR04HS model with $4.5 \mathrm{~Hz}$ sensors of was used to make a comparison with MicDAC. The signals recorded simultaneously by MicDAC and GeoBox are shown in Fig. 8a and b. Log-MT software was used to monitor and record the signals with GeoBox. Two different gain levels, 46 


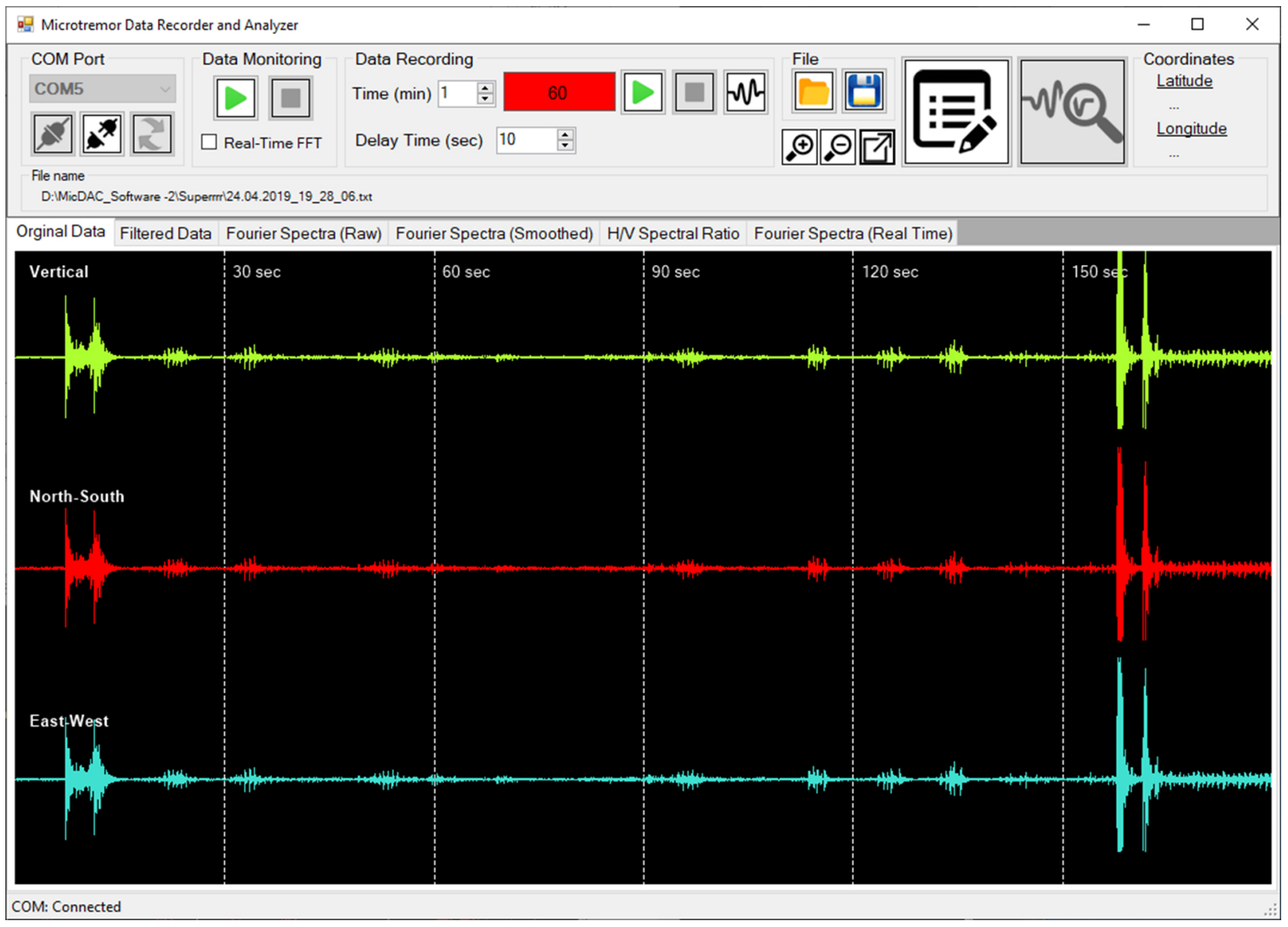

Figure 5. Screenshot of MicDAC-GUI and detected signals using a $4.5 \mathrm{~Hz}$ vertical geophone connected to each channel input.
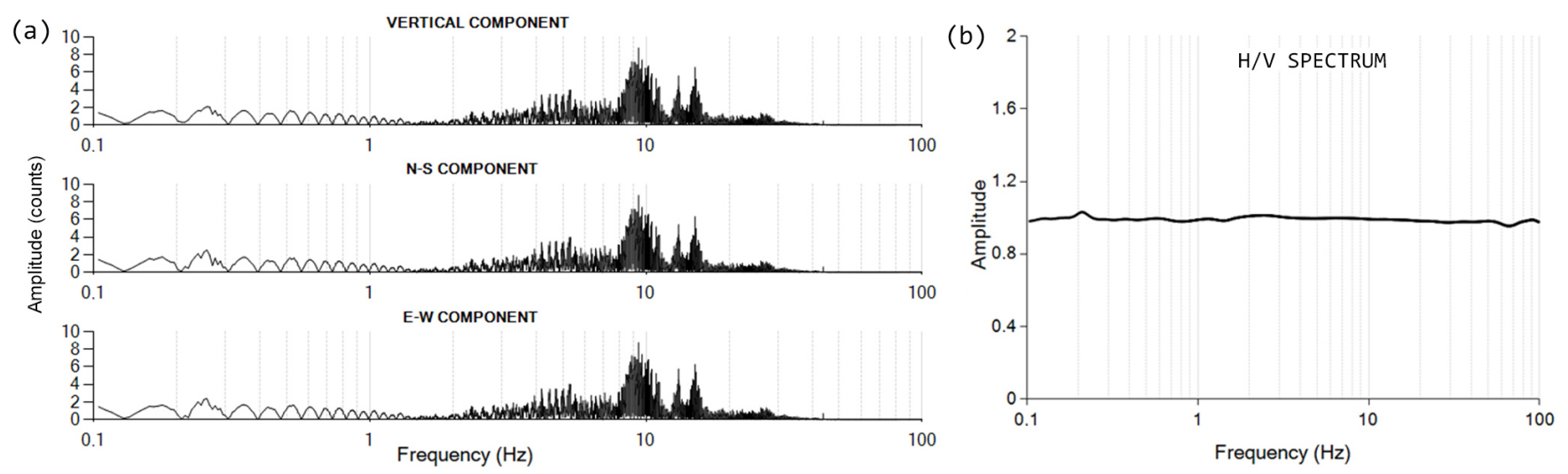

Figure 6. (a) Fourier spectra for the recorded three-component data during the second channel consistency test; (b) H / V spectral ratio.

and $60 \mathrm{~dB}$, were used in the signals recorded with MicDAC. As a result of this comparison in the time domain, a good correlation between the recorded signals using GeoBox and MicDAC was observed. This similarity was also observed in their frequency spectra (Fig. 8c). In addition to the comparisons in the time and frequency domains, their $\mathrm{H} / \mathrm{V}$ spectral ratios were also obtained using the Geopsy software (Fig. 9a and $\mathrm{b}$ ). The obtained $\mathrm{H} / \mathrm{V}$ peak frequencies and amplitudes are given in Table 2. A good correlation was observed between the calculated $\mathrm{H} / \mathrm{V}$ peak frequencies and amplitudes. The main reason for the differences in the amplitudes of the $\mathrm{H} / \mathrm{V}$ curves at frequencies below $2 \mathrm{~Hz}$ is related to the elec- 


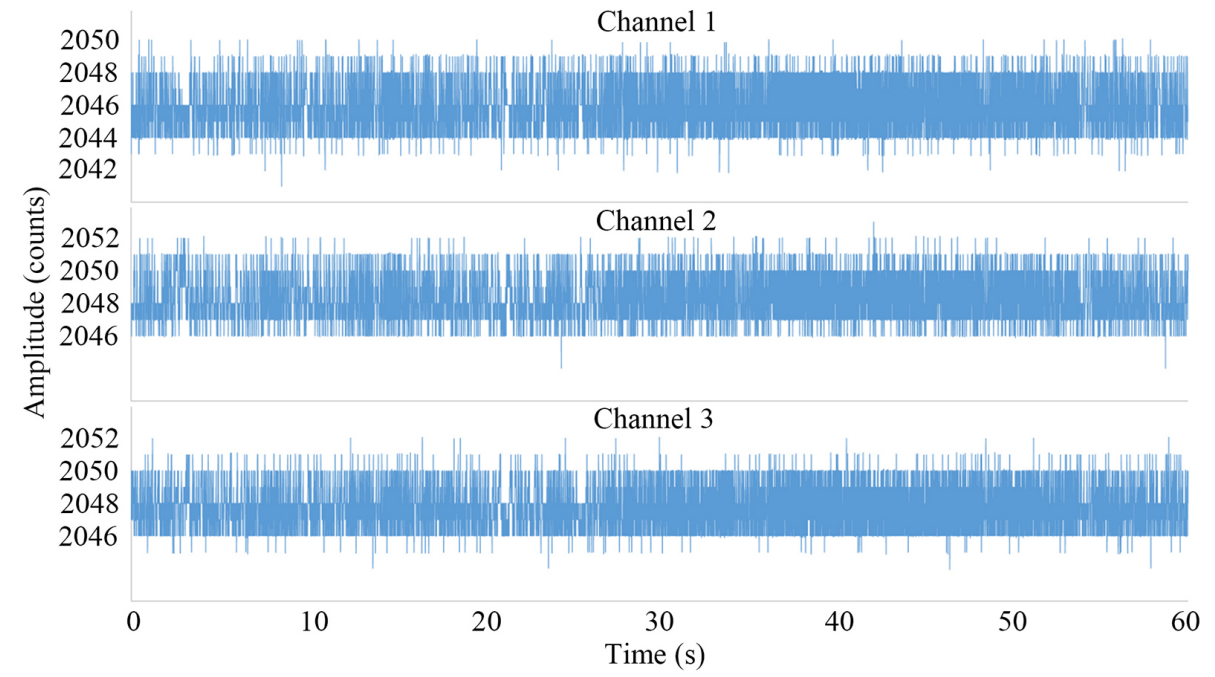

Figure 7. Internal noise measurements for each channel.

(a)

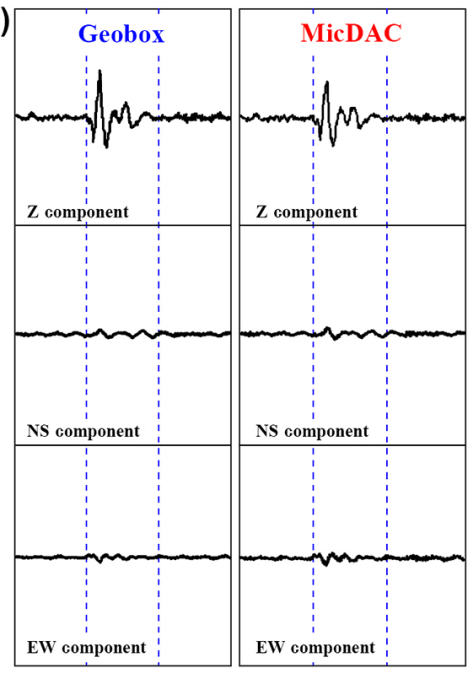

(b)

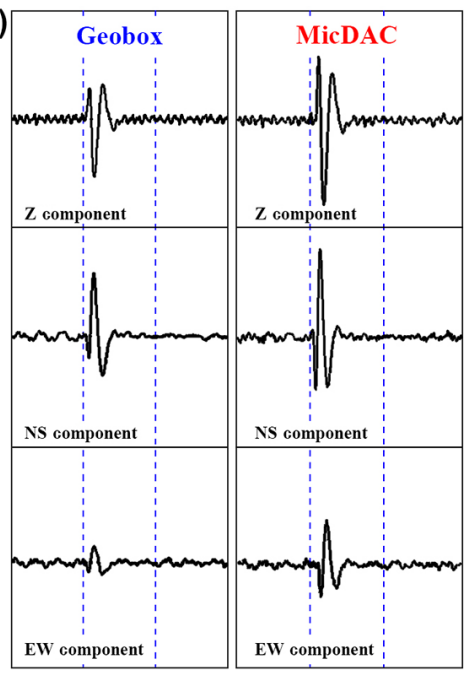

(c)

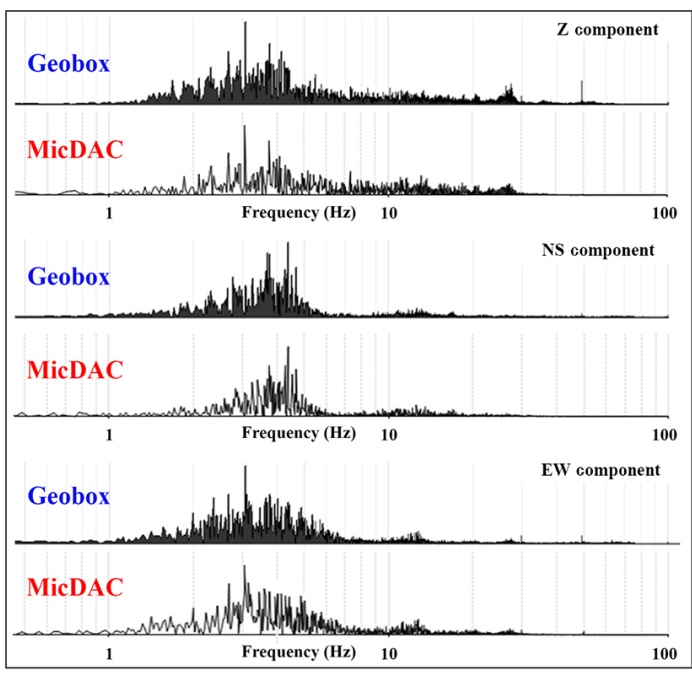

Figure 8. Three-component seismic data recorded simultaneously using both devices: (a) MicDAC with $46 \mathrm{~dB}$ gain and (b) MicDAC with $60 \mathrm{~dB}$ gain. (c) Comparison of Fourier spectra of recorded three-component microtremor data using GeoBox and MicDAC.

tronic design of GeoBox. GeoBox has an electronic architecture that can obtain a flat band wider than the natural band of the geophone embedded in the instrument. Therefore, it obtains better sensitivity at low frequencies.

\section{Experimental study}

Another test measurement was conducted to test the performance of MicDAC in field conditions and to compare the obtained results with a previous study. For this purpose, a previously measured area was selected for recording ambient noise. The measurement point is located in the Kartepe district in the Marmara region, Turkey (Fig. 10a).
This region is in the middle of the Izmit Basin, and the upper strata of this basin are composed of alluvium deposits consisting of silt, sand, gravel, and clay. In this region, a large-scale study for site classification and seismic hazard assessment was already conducted by the Marmara Research Center of TÜBİTAK and Greater Metropolitan Municipality of Kocaeli (Özalaybey et al., 2008, 2011). According to their study, the thickness of the sediments in the Izmit Basin was calculated as approximately $715 \mathrm{~m}$. Especially in the regions located in the middle of the Izmit Basin, it was found that the $\mathrm{H} / \mathrm{V}$ peak frequency varies between 0.2 and $1.0 \mathrm{~Hz}$ and the corresponding magnification values are 5-6 times (Özalaybey et al., 2008).

Ambient noise was recorded during a period of $20 \mathrm{~min}$. The relation between the expected minimum frequency and 

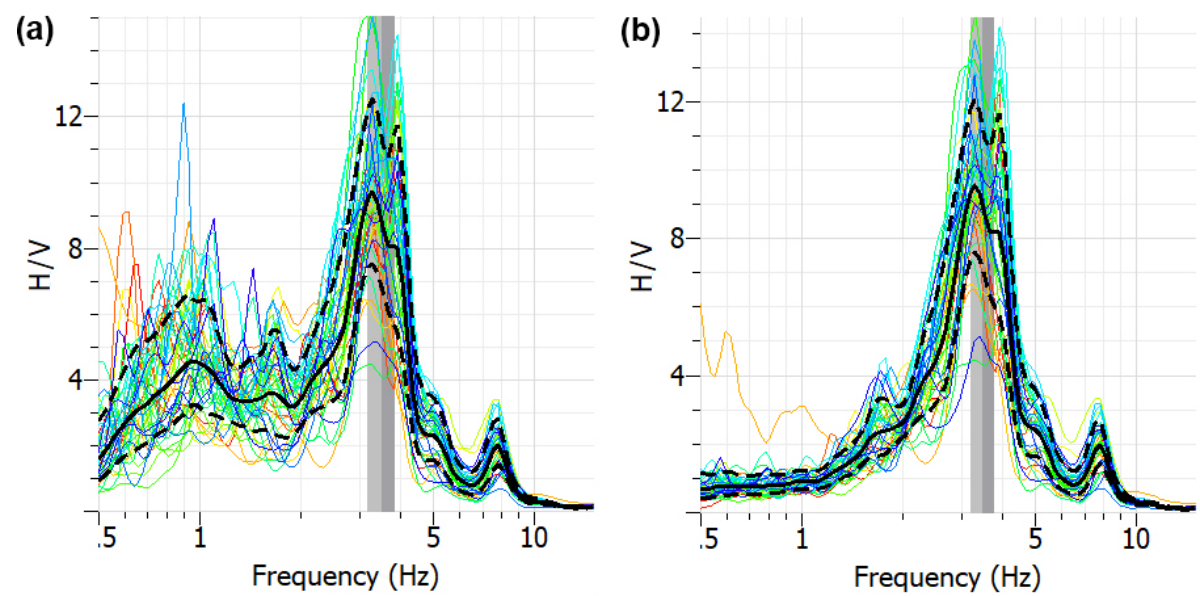

Figure 9. The obtained $\mathrm{H} / \mathrm{V}$ spectral ratios of recorded data by (a) GeoBox and (b) MicDAC.

(a)

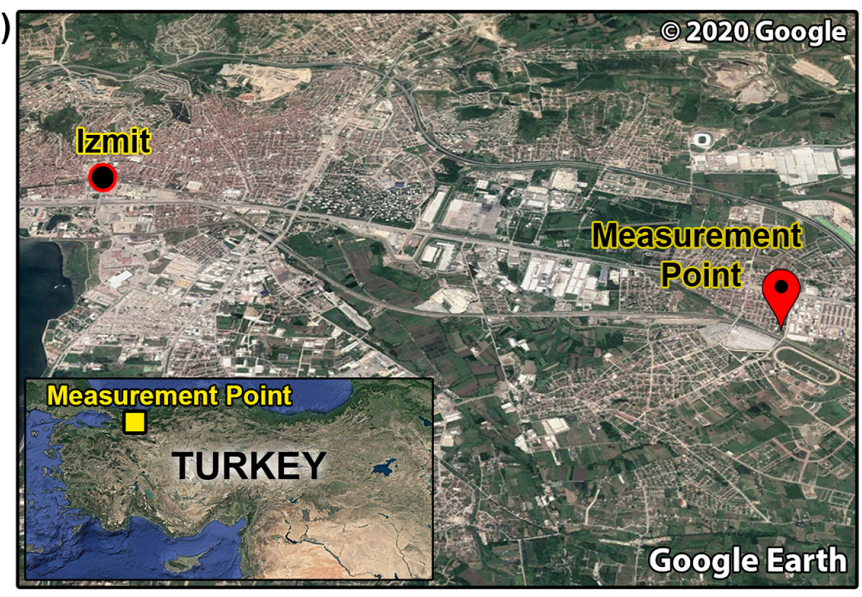

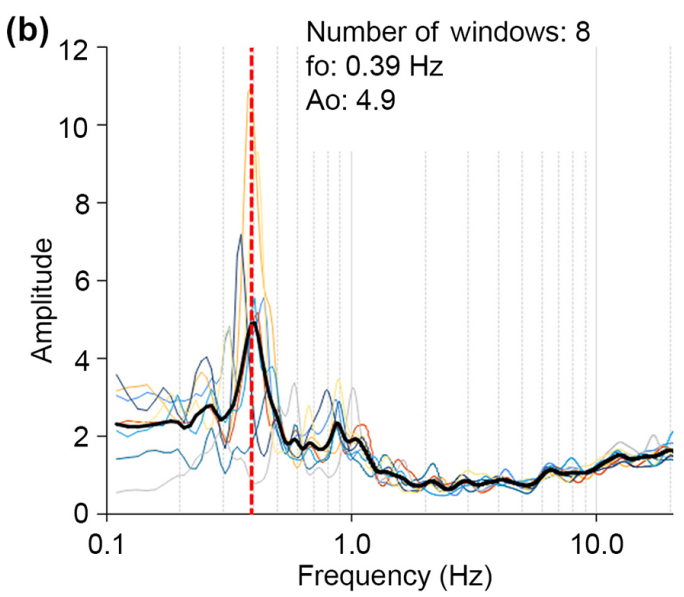

Figure 10. (a) Location of the test measurement point in Google Earth@ view; (b) H / V spectral ratio.

recording duration is explained in the SESAME report in detail (SESAME, 2004). The recorded signal was split into 14 time windows of $81.92 \mathrm{~s}$, and eight of these time windows were used for the analysis; $5 \%$ cosine tapering and $10 \mathrm{~Hz}$ low-pass filtering operations were applied to the selected windows, and Fourier spectra for each window were calculated. The Konno-Ohmachi filter with bandwidth $b=40$ was used to obtain the smoothed Fourier spectra. Then H / V spectral ratios were calculated for each window. Finally, the $\mathrm{H} / \mathrm{V}$ peak frequency and amplitude for the measurement point were determined as 0.39 and $4.9 \mathrm{~Hz}$, respectively (Fig. 10b). These findings show that the obtained results are consistent with the literature (Özalaybey et al., 2008).

\section{Conclusions}

The aim of this study is to develop a low-cost, computeraided, and Arduino-based three-component microtremor data acquisition and analysis system using basic electronic components, integrated circuits, and the Microsoft .NET Framework 4.5.2 application development platform. The designed external hardware can be easily assembled by readers and controlled through a developed graphical user interface using C\# language. This software allows for the monitoring and recording of three-component microtremor data and analyzing the recorded data using the horizontal-to-vertical spectral ratio $(\mathrm{H} / \mathrm{V})$ technique. In this way, the peak frequency and amplitude of the $\mathrm{H} / \mathrm{V}$ curve can be estimated. Channel consistency, internal noise measurement, and comparison tests were performed to demonstrate the accuracy and precision performances of the proposed system. In the channel consistency test, it was shown that the error percentage of the difference signals was lower than $1 \%$. In addition, it was shown that the $\mathrm{H} / \mathrm{V}$ is equal to 1 when a single sensor is connected to each channel input at the same time. In the internal noise measurement test, the noise levels for three channels were observed as approximately \pm 3 counts. In particular, the $\mathrm{H} / \mathrm{V}$ curves obtained from data recorded 
simultaneously with MicDAC and GeoBox and their peak frequencies and amplitudes proved the reliability of the proposed system. Finally, an experimental study was performed to test the performance of MicDAC in field conditions. The obtained $\mathrm{H} / \mathrm{V}$ peak frequency and amplitude from the experimental study were compared to a previous study, and a good correlation was shown between them. Therefore, it can be concluded that MicDAC is a suitable and inexpensive alternative system for three-component microtremor measurements and $\mathrm{H} / \mathrm{V}$ analysis.

Code availability. The MicDAC software folder with a size of $10 \mathrm{MB}$ contains an Arduino sketch program, executable file folder, MicDAC open-source software files, and readme file. The MicDAC software was developed by using the C\#.NET language. It is based on Microsoft Windows OS and Framework 4.5.2. The developed graphical user interface, device firmware, and other supplementary files can be supplied from the author or downloaded from GitHub, a web-based repository hosting service: https://github.com/ozkankafadar/MicDAC (https://doi.org/10.5281/zenodo.4009796, Kafadar, 2020).

Competing interests. The author declares that there is no conflict of interest.

Acknowledgements. I would like to thank the Sentez Earth and Structure Engineering Limited Company for allowing me to use their laboratory and equipment.

Review statement. This paper was edited by Ciro Apollonio and reviewed by two anonymous referees.

\section{References}

Aki, K.: Space and Time Spectra of Stationary Stochastic Waves with Special Reference to Microtremors, B. Earthq. Res. I. Univ. Tokyo, 35, 415-456, 1957.

Douze, E. J.: Signal and noise in deep wells, Geophysics, 29, 721732,1964

Fisher, D. K. and Gould, P. J.: Open-Source Hardware Is a LowCost Alternative for Scientific Instrumentation and Research, Modern Instrumentation, 1, 8-20, 2012.

Frantti, G.: The nature of high-frequency earth noise spectra, Geophysics, 28, 547-562, 1963.

Huang, H., Lee, D. H., Chang, K., Li, W., and Dev, A. T.: Development of mobile platform for indoor positioning reference map using geomagnetic field data, Computers and Electrical Engineering, 68, 557-569, 2018 .
Kafadar, O.: ozkankafadar/MicDAC: MicDAC, Zenodo, https://doi.org/10.5281/zenodo.4009796, 2020.

Kafadar, O. and Sertcelik, I.: A computer-aided data acquisition system for multichannel seismic monitoring and recording, IEEE Sensors J., 16, 6866-6873, 2016.

Kanai, K.: On the spectrum of strong earthquake motions, Primeras J. Argentinas Ing. Antisismica, 24, 68-73, 1962.

Katz, L. J.: Microtremor analysis of local geological conditions, B. Seismol. Soc. Am., 66, 45-60, 1976.

Khan, K. A., Akhter, G., and Ahmad, Z.: DigiSeis-A software component for digitizing seismic signals using the PC sound card, Comput. Geosci., 43, 217-220, 2012.

Konno, K. and Ohmachi, T.: Ground-Motion Characteristics Estimated from Spectral Ratio between Horizontal and Vertical Components of Microtremor, B. Seismol. Soc. Am., 88, 228241, 1998.

Llorens, J. L. S., Merino, J. J. G., Caturla, J. J. G., Eslava, P. J., Cintas, S. R., and Herranz, J. R.: Development and programming of Geophonino: A low cost Arduino-based seismic recorder for vertical geophones, Comput. Geosci., 94, 1-10, 2016.

Llorens, J. L. S., Merino, J. J. G., Caturla, J. J. G., Eslava, P. J., Cintas, S. R., and Herranz, J. R.: A low-cost three-component seismic noise recorder for the application of the $\mathrm{H} / \mathrm{V}$ method, Sensor. Actuator., 269, 342-354, 2018.

Nakamura, Y.: A method for dynamic characteristics estimation of subsurface using microtremor on the ground surface, Quart. Report Rail. Tech. Res. Inst., 30, 25-33, 1989.

Özalaybey, S., Zor, E., Tapırdamaz, M. C., Tarancığlu, A., Özalaybey, S. Ç., Erkan, B., Karaaslan, A., Alparslan, E., Ergin, M., Ergintav, S., and Tan, E.: Kocaeli İli için Zemin Sınıflaması ve Sismik Tehlike Değerlendirme Projesi, TÜBITAK, 5057105, 1190, 2008.

Özalaybey, S., Zor, E., Ergintav, S., and Tapırdamaz, M. C.: Investigation of 3-D basin structures in the Izmit Bay area (Turkey) by single-station microtremor and gravimetric methods, Geophys. J. Int., 186, 883-894, 2011.

Percival, D. B. and Walden, A. T.: Spectral Analysis for Physical Application, Cambridge University Press, London, 187-330, 1993.

Puente, S. T., Ubeda, A., and Torres, F.: e-Health: Biomedical instrumentation with Arduino, IFAC-PapersOnLine, 50, 91569161, 2017.

SESAME: Guidelines for the implementation of the $\mathrm{H} / \mathrm{V}$ spectral ratio technique on ambient vibrations: measurements processing and interpretation, European Commission-Research General Directorate, Project No. EVG1-CT-2000-00026, 2004.

Texas Instruments: Single Supply, MicroPower Instrumentation Amplifier, INA122 datasheet, 1-14, 1997.

Weller, C. E.: Seismic Exploration Method, U.S. Patent, 3.812.457, 1974. 